\title{
The challenges of an effective and sustainable health system in developing countries. The case of Madagascar.
}

\author{
Kasy Emile ${ }^{1}$ \\ University of Toamasina Madagascar \\ Mail adresse : kasyemile@yahoo.fr
}

\begin{abstract}
The health system in developing countries has been very controversial. Making the comings and goings between an interventionist spirit of a welfare state and liberal ideas of justice, the system has difficulty in having credibility vis-à-vis the care services to the population. The case of Madagascar, a country among the poorest embody this drift of health system. A large proportion of households still do not have access to health services, while the poor do not have any support for their situation. The application of the principles of Alma Ata followed by that of the Bamako Initiative did not produce the desired effects. This work will then attempt to unravel the reasons for existing health systems problems, while exploring ways to contribute to reflections for a sustainable health system that people need for their well-being.
\end{abstract} Key words: Madagascar - health system - Alma Ata- Initiative of Bamako - efficiency

\section{Introduction}

The definition of health as "a comdplete state of physical, mental and social well-being" (WHO) indicates that it has a multidimensional aspect that affects both individual and collective life. This social and collective aspect places its consideration in a prime public interest where the state plays a key role. History in the world teaches that the state has always played a big role in developing the health of the population. In developing countries, this role, so preponderant, has passed all the tests to the extent that it has always changed in the course of history without following the standard evolution of things. If in the so-called "rich" countries the state has played a precise and evolving role in the development of an evolving health system and adequate financing, in developing countries, it is always a question of knowing How will the state go about it? Since the late 1970s, while the Community of Developing Countries has found more or less standard pathways in the structure and system of health provision, unlike rich countries, it is stumbling on funding. The story has brought out information that deserves to be excavated: since the declaration of Alma Ata where the States have opted for free health care until the initiative of Bamako asking the population to pay the costs of care, there is a symmetrical positional deviation. The common point is that neither has solved the problem. It is to make a contribution in this dilemma of choice of system and policy that this work is invited in the debate. The main question is to ask why Alma Ata to the Bamako Initiative, the developing countries accumulate from failure to failure so far and what alternatives or horizons could revive the reflection and debates in view for a proposal of possible alternatives for the population.

\footnotetext{
${ }^{1}$ Kasy Emile Mail adresse : kasyemile@yahoo.fr Tel : + 261321198001 Uuniversity of Toamasina Madagascar
} 
1- Health system practices in Africa.

\section{1-1- The problems of the health system in African environment seen by the literature.}

The health system is defined as "all organizations, institutions and resources whose purpose is to improve health ..." .In this way, "... it includes all activities whose essential purpose is to promote, restore or maintain health. (WHO, 2000). This testifies to the importance of this device in improving the health of the population, one of its major objectives. The role of the state is there to promote health using a policy and health system performance, the positioning of individuals and the community is quickly invited into the debates.

\section{- Health system in developing countries and political visions}

Given the historical, economic and political context in which developing countries have been living since independence, health has not been spared by these controversies. Since health is both an individual and collective good, improving it involves a multidimensional vision. And the contradictions of thoughts are very much invited. Two main positions are therefore face to face with regard to the vision of health care: interventionist thinking and liberal thinking. The interventionist thinking of the spirit of the welfare state that puts the preponderance of the state in the device rolls for "health for all" with the strong idea of WHO advancing the collective care of health. Proponents of this idea pound the free access of everyone to care services. It is therefore based on an egalitarian idea of justice where everyone must have the care they need according to their condition.

The other thought that is a liberal conception of justice insists that the health system must function in such a way that everyone is called to social and financial responsibility for their health. The system therefore freely puts each individual before his solvency. With the putting into play of individualism and competition.

This dichotomy of the political vision of the health system has persisted throughout the history of the health system in developing countries.

In the 1970s, years after the independence of these countries, their economic problems continued to worsen with stagnant growth rates, deficient public finances and poor economic performance. And, without delay, these problems have had an impact on the functioning of the health system and the health of the population itself. A very low life expectancy, very high mortality rates caused by problems of access to care have challenged the respective governments with the presence of the WHO to seek ways to significantly improve the health of the population. Then came the idea for the governments concerned to set common goals for their health policy: health for all by the year 2000. It was the Alma Ata Conference in 1978 that laid down the principles based on Facilitating access to care by the mass of the population and giving the community a greater say in health. For access issues, Alma Ata laid the principle of "free care", following the principle of collective care with the strengthening of the role of the state. The goal of free education was to increase access to public health care without financial barriers given the socio-economic conditions in which it lives.

But it is precisely here that the history of the health system in the developing countries knew a paradigm. Continuing to cope with the growing economic problems, states soon became aware of problems with their health system: with a budget becoming more and more problematic, they could not meet the needs health center materials. This made send to the wall the principle of free care where very deep gaps exist whose main needs relate to the pharmaceutical needs of patients. The system could not work and according to Joseph Brunet-Jailly, with what it assumes to be a hole, the principle of gratuitousness was a fiction. Others (Fassin, 2000) saw that from the beginning, Alma Ata had remained in a very general statement and that the implementation becomes secondary to the ideals invoked. The intentions would be even general and abstract and the components exhaustive and banal. 
Bamako Initiative (IB) and Cost Recovery: Response to Alma Ata.

The Bamako Initiative (IB), still based on the "Health for All" vision, is a logical continuation of what has happened in the application of the Alma Ata principles. As a result of the economic problems in which countries embarked in the 1980s with adverse health consequences, WHO, with the assistance of UNICEF, made a proposal. A proposal worked in Bamako in 1987 and whose main objective was the revival of primary health care. The guiding principles concern eight points including access to care for the whole community, decentralization, a substantial contribution, the concept of essential drugs, exemptions and subsidies for the poor (WHO)

In addition, the Bamako Initiative aims to:

- strengthen management and financing mechanisms at the local level;

- promote community participation and strengthen local management capacity

- strengthen mechanisms for the supply, management and use of medicines essential;

Based on a community process with management responsibility at local level, this proposal coincided in terms of financial support for the idea of payment and direct participation of patients. This de facto financial participation should then lead to the reduction of state participation, while at the same time ensuring that the poorest have access to care. This is why, at first glance, the IB is often perceived as a simple technical reform of the financing of health services. At this stage, we move from an approach of collective management of interventionist obedience of the principle of Alma Ata to a liberal perspective of individual health care of the Bamako Initiative.

The cost recovery will therefore meet the principle of continuous essential drug supply and the continuity of the fund cycle that will ensure the functioning of the system. But some problems come to constitute limits to these recoveries. First, revenue from cost recoveries was not enough to ensure that the deficit of the state was reduced for the operation of the system. Second, in most cases, the system has been initiated in the presence of funders to the point where it is very difficult to identify the separations between the two. In the same logic, separating the costs of intervention on both sides is a very difficult undertaking. This raises doubts about the clarification of the durability and sustainability of the system.

Thirdly, this is one of the crucial points of the system: a fair policy aims to ensure equal treatment for everyone, regardless of their financial abilities. Yet, pricing, which involves the individual solvency of individuals, calls into question this egalitarian approach to equity. And despite the fact that certain principles come to the rescue to take care of the poorest (in the Rawlsian conception), the financial participation with the pricing can put in question the access of a part of the population to the care. account of the ability of the population to pay for health care compared to that of the state has been minimized.

and the only way to ensure equal access to care is free or social insurance. We will come back to it.

\section{- Bamako Initiative: Efficiency versus equity}

For a health system WHO (2000) defines for a health system three main objectives, including (i) improvement of health, (ii) responsiveness (the capacity of the system to meet the expectations of the population) and (iii) the fair financial contribution. In the logic where the effectiveness of a system is measured by the achievement of its objectives, efficiency and equity interlock and influence each other.

Based on the community-based approach of the Bamako Initiative, community participation through the transfer of jurisdiction and responsibility at the local level is one way to improve system efficiency and equity. This assumption of responsibility at the local and community level plays a big role in improving the health and responsiveness of the system (relevance) and especially in the fair financial contribution (equity) 
Starting with the problems of free healthcare where the system went bankrupt and the population has finished paying for care, the adoption of a certain economic rationality by the resources collected would improve the quality of care. and equity through reallocation of expenditures.

Countries have tried to put the system in place, having gained momentum from international partners. Moreover, decisions are made at a high international level and would hope for technical and financial support. Then were applied everywhere: management committee, decentralization, pricing with cost recovery. If the system seemed to work for a few years, it began to gradually encounter problems of functionality, a decrease in the supply capacity of drugs because the recipes were used for many more things, etc ... It appears as Tizio mentioned that "... all the worries focused on the organizational realization at the expense of the effective long-term effectiveness of the principle ...".

\section{- And equity?}

It must be said that aiming for equity is to take on the challenge of targeting inequalities in the health of the population. Equity means equal access to all people regardless of their social, geographical or financial standing. WHO in its vision of Health for All specifies equity as (i) equal access for equal need to available care, (ii) equal use for equal need and (iii) equal quality of care for all. In this momentum, a definition (Flori \& Kaddar, 1996) sheds light on us: "The search for equity is a process that aims to take all possible measures to reduce differences in the field of health between social groups or between geographical areas by interventions either in the health sector or in other sectors ". But it should be noted that there are two notions of equity: horizontal equity that advocates equal care for equal needs, as opposed to vertical equity that recommends more care for people with high needs. It is clear that in practice the pursuit of equity in both directions is a very difficult exercise. Nevertheless, the theories of the two prominent economists reinforce these ideas about equity. The first from Rawls concerns social justice where the differences between the advantaged and the disadvantaged must be eliminated as much as possible. First, the principle states that "every person has the same right to the highest possible level of basic freedoms, compatible with a similar level of freedom for others". Secondly, there must be equality of opportunity for all.

These ideas are complemented by those of Amartya Sen Justice must consider the fact that between two beneficiaries, the one who is more vulnerable must have much more support in proportion to their capacity levels called capabilities (Sen, 2000).

But how was all this done in the Bamako Initiative? It is true that the free treatment of the principle of Alma Ata offered equity an ideal boulevard. Masi economic and financial equilibrium logic broke very quickly the way. In order to respond to this bankruptcy, for a decent quality of care for the population, the Bamako Initiative has introduced the principle of cost recovery known as the financial participation of users through the pricing of care services. But very quickly, the individual character of the payment encountered a problem of funds. On the one hand, individual payment does not guarantee individuals a guarantee of being able to pay for themselves, since they are subject to the enormous financial risks they face in the event of illness in relation to their income level which are low. On the other hand, pricing, which implies the solvency of individuals, calls into question the egalitarian approach to equity.

It is this cocktail of different elements that are difficult to coexist that has characterized the overall implementation of the health system in Africa. In all, the difficulties are as follows: the system, which has been endorsed by international bodies, has been set up focusing on the organizational parts. If proximity management has given impetus through community-level 
accountability, the functionality of the system has stumbled on a wall. Pricing involving the population to pay the famous financial participation has encountered several problems. On the one hand, it required the financial solvency of users that is not always obvious, given their standard of living. The principle ignored neither their ability nor their willingness to pay. On the other hand, financial participation has biased the consideration of equity because it does not ensure the equalization of individuals with the right to be treated in financial terms. And in general, the financial repercussions for the functioning of the health structures were not guaranteed in the long term.

\section{1-2- Realities of the functioning and results of the health system in Madagascar.}

- The general context of Madagascar: economic developments

Madagascar is one of the countries of the Indian Ocean located in the South East of Africa.400km separates it from Mozambique with the Canal which bears the name of the latter. History maintained that the settlement of this Great Island of the Indian Ocean dates back to the first millennium AD. The first to arrive are Indonesians who have approached the north-west and have progressed to the center for centuries. Then, Africans crossing the Mozambique Channel moved to the Southwest. In the second millennium, it was the Arabs who competed with Indonesians in trade and set up their trading posts in the northwestern coast of the island. In the sixteenth century, Europeans approached it and it is the beginning of European attendance in the Big Island (Portuguese, English and French). Until the end of the 1800s, Madagascar experienced royal periods where Kings and Queens succeeded each other with different positions from each other especially vis-à-vis the relations and entries of foreign countries. They ended in 1896 when, after a confrontation with France, Madagascar was put under French protectorate from where the period of colonization from the year 1896. For 60 years the big island was thus French colony with what this implies as internal and external functioning of economic and social lives. Provoked by the context both internally and externally, Madagascar had its independence in 1960. Then came the social-democratic (1960-1972) and socialist (1975-1985) regimes. In the 1980s, caught up in problems With a deep economic and economic performance, the country turned to the Bretton Woods institutions to remedy its economic problems with the Structural Adjustment Program. Since the 90s, Madagascar has applied in turn and with each other the fight against poverty, human development and the preservation of the environment. But in reality, all this did not put the Big Island in the tracks of development. The purchasing power of its population is cut by one third of its value between 1950 and 2010 (Razafindrakoto, 2013) with an average of $-1 \%$ per year for the growth rate.

Geographically, Madagascar is an island of temperate tropical climate where humidity and high temperature are combined. This environment greatly influences the health conditions of the population. Malaria (malaria) is a dominant disease to this day and this disease alone occupies $25 \%$ of the outpatient consultations of the Basic Health Centers in Madagascar. $(\mathrm{MOH})$

According to its political and economic history and its geographical location, the Malagasy health system has experienced all endogenous and exogenous influences.

\section{- History and evolutions of the health system}

Long before royalties, Malagasy people have lived for a long time using traditional healers' knowledge of healing. They then used the accompanying plants or plant extracts or other ancestral processes such as rites or others. These so-called traditional practices continued until they reached Europeans in the 1800s, from which Malagasy used so-called "modern" medical procedures. The due have thus always continued to cohabited since this period. 
With alternations more or less eventful kings where the issue of religion played major roles, and where Europeans began to know a rush, Madagascar saw his medicine evolve while continuing to receive European missions. At that time, there had been training of Malagasy young people on the so-called modern medicine trials. From these frequentations, there had been the birth of a Norwegian hospital in 1869, the Malagasy Medical College in 1870 to train Malagasy doctors and nurses, and a royal dispensary in 1875. And in 1880, there was the opening of the Medical Mission by the London Missionary Society

When Madagascar was colonized in 1896, the governor, General Gallieni, instituted the Indigenous Medical Assistance (AMI). It was a health system designed to treat the sick, fight against endemic diseases and epidemics and finally, to promote the birth rate in the face of the very high infant mortality rate of the time. It was then to improve the lot of the population by health advice, especially for rural people who were entirely dedicated to healers and wizards. The MAI provided free medical care and medicines and was financed by an autonomous health budget. This budget supported all operating expenses (salary, maintenance work, drug purchases and transportation costs.

The receipts consisted, on the one hand, of proceeds from the sale of medicines, day-care fees paid to the sick, and, on the other, from a tax of assistance that any poor, non-poor adult Malagasy had to pay.It was the very first structured health system as such.

The central administration of the MAI was in the capital is placed under the responsibility of a General Physician of the colonial troops. The colonial territory was divided into medical districts corresponding to an administrative territory of a province or to an important district which constituted the health unit.Outside the capital, health facilities were run by Malagasy doctors and midwives. Hospitals, maternities, dispensaries, medical and delivery posts were distinguished.This system has evolved progressively and continuously (in qualitative and quantitative dimensions) until independence and afterwards to achieve the current health system.From all the foregoing, it is deduced that the Malagasy health system has taken a lot on the European footprint. However, this has not eliminated traditional practices that have persisted to this day, particularly in rural areas.

From 1960, the year of independence, the first President of the Malagasy Republic undertook a takeover of the health system by adopting various Public Health Code for the promotion and management of Malagasy health. Comprising eight books, the code defines from one area of health to another: health control, the conditions of legal exercise of the medical professions, drugs, public health institutions, creation and opening of health institutions , the fight against social ills, the health protection of the family and the laboratories

In 1971, (ten years after independence), a decree was promulgated fixing the nomenclature of health facilities, whose hierarchy was constituted by:

- general and primary hospitals (at the capital level)

- single and surgical secondary hospitals (at district or provincial level)

- medical centers and health posts (at commune level)

- delivery and nursing stations (at village level)

During the Second Republic (1975-1991), adopting a socialist orientation, health policy was based on:

- the preponderance granted to preventive medicine over curative medicine,

- the primacy of community medicine over individual medicine

- increased interest in the rural mass,

- and the importance of health education.

In a simplified way, the functioning of the health and care system is as follows: 
- basic health centers (formerly medical centers) are the first contacts of the population with health services,

- Cases that can not be processed at this level

We can then say that Madagascar, despite its somewhat unusual history with its insularity in the Indian Ocean, is one of the examples of contradictory developments in health systems in developing countries. What are the realities?

\section{- Realities of the health system: access to care, efficiency, and equity}

In the 1970s, the presence of the state, as history has shown, meant that health expenditures were provided by the state through taxation. But in view of the increasingly disastrous economic situation, the state's resources have become increasingly weak, which has led to a fall in the quality of care provision at the health facility levels. And, faced with this, the population is in a critical socio-economic level with very low incomes. WHO and developing country governments have implemented free health care to improve access to care. But there is a reality, given the economic level of the Big Island, the budget allocated to health was still very low: 3 to $4 \%$ of GDP for decades and forecasts even give a rate of less than $3 \%$ in 2018 . The truth arises: a state with limited means can not offer a good quality of care that is delivered free of charge. Very quickly, the problems were felt. Health centers and facilities are asphyxiated with stockouts of medicines and consumables. In fact, patients have been forced to pay for treatment, especially for drugs that account for $55 \%$ of expenditures. Free admission was therefore a vain word.

Thus, instead of improving access to care, ten years after the application of the system, Madagascar still has 60 to $70 \%$ of households (WHO) who did not have access to care.

This, as we already know, has had the Bamako Initiative installed, by adopting the payment of care under the name financial participation of the users. On the government side, this principle has respected cost recovery in order to compensate for the deficits that have come together.

The principles were only applied in Madagascar in the mid-1990s with progressive application.

At the level of the basic health centers, the cost recoveries made it possible to ensure the nonstop supply of the drugs which could be renewed in time. This reassured the population. Combined with community involvement in its management, there was some functionality in the system.

In hospitals, the effects are much more significant: the recovery of costs by the financial participation of the users, even progressive have given fruits. For example, in the first University Hospital in Madagascar, which applied it, revenues started at $13 \%$ of the total hospital revenue in 1992 (beginning of the application of the principle) up to $96.68 \%$, in 1996. (RICHARD, 2005). As a result, they have been able to progressively serve the hospital's routine expenses up to the motivation of the staff.

And this experience has been extended in other CHUs in the country. In these hospitals, the first year of application has already seen the constitution of $40 \%$ of revenues (subsidies) from the state.

But this very positive aspect at the beginning hid some imbroglios over the years, points that were underestimated at the beginning. First of all, if the receipts were able to ensure the current expenses in the hospitals it was because the said centers, compared to the health centers have a diversity of health services which make return money (hospitalization, outpatient consultations, x-rays and medical images, etc.) The real problems have been in basic health training, the first contact to the care services of the population. 
Financial participation constituted a certain barrier at the household level: the utilization rate of CSBs did not improve: $41.7 \%$ in 1999, a few years after the implementation of the Bamako Initiative, the rate was 41.6 in $2005,32.7 \%$ in 2010 and 32.3 in 2014. A deterioration in access to care. And according to the Demographic and Health Survey in 2008-2009, 55\% of people have put forward a money problem to access care. The expected efficiency in meeting the care needs of the population was therefore very small

\section{- Equity: Inequalities maintained}

Equity in care is one of the objectives of the Bamako Initiative. If Malagasy health policy stipulates the equality of people for health care, that all people have the right to be treated, in reality it manifests itself differently.

If geographical equality is still a major challenge for Madagascar, equality in financial terms is a big problem. The financial participation of the users who is individual does not put all people in the same footing of equality. According to the expression used by Tizio and Flori vis-à-vis the income, the purchasing powers as well as the ability to pay (ability to pay) and by logic the willingness to pay have not been considered.

According to a study already conducted by CREDES and quoted by Richard, the health expenditure of the richest and poorest households is vastly different: if the richest pay their health expenditure to $3.9 \%$ of their annual income, the poorest incurs $19 \%$ of their income for theirs, which is 5 times higher than that of the richest households. Financially, people are not equal before the doors of health centers.

Even though the system has tried to provide devices for the poorest natives, two major problems have been tackled. The first, of an organizational nature, concerns the difficulties of discerning all those who are indigenous. Psychological and sociological considerations are therefore at stake. The second is financial: facing the difficulties of the individual financial participation, the health centers, after removing the shares for the replenishment of medicine, do not have many things as remaining revenue to take care of the natives. so few are they.

The following table, which deals with health financing and which shows the share of the stakeholders shows how far the Malagasy health system has not planned a financial perspective, a guarantee of equity in the principles that have been successively applied.

Table 1 : Health financing in Madagascar

\begin{tabular}{|l|l|l|l|}
\hline Years & 2003 & 2007 & 2010 \\
\hline Publics funds & $32 \%$ & $49 \%$ & $14 \%$ \\
\hline Households & $20 \%$ & $23 \%$ & $40 \%$ \\
\hline Rest of the world & $37 \%$ & $17 \%$ & $42 \%$ \\
\hline Private funds & $11 \%$ & $11 \%$ & $4 \%$ \\
\hline
\end{tabular}

Source : Ministry of health (Health sector Devlopment Plan, 2015)

With a very high participation in health expenditure, the Malagasy health care system does not respond to the socio-economic considerations of the population, leaving them plagued by health expenditure.

Table 2: The problems of the functions of the health system in Madagascar

\begin{tabular}{|l|l|l|}
\hline Relationships & Equity & Efficacy \\
\hline Health care access & $\begin{array}{l}\text { Discrimination of the } \\
\text { poorest }\end{array}$ & Weakness of answers \\
\hline $\begin{array}{l}\text { Financial } \\
\text { solvency }\end{array}$ & $\begin{array}{l}\text { Problème of constitution of } \\
\text { equity funds }\end{array}$ & $\begin{array}{l}\text { Dégradation of quality to } \\
\text { care }\end{array}$ \\
\hline
\end{tabular}


Autorr : From the health system functions defined by the WHO

A kind of self-perpetuating vicious circle persists at the level of the health system:

- The "health for all" objective is affected by the difficulty of households to financially access care

- The low budget of health centers affects the effectiveness of services through the quality of care.

- The problems of access to care and low income are self-perpetuating with the virtual absence of the equity fund for the natives.

The functionalities of the health system encounter inextricable parametric difficulties that have an impact on its ability to improve the health of the population, its main objective

\section{2- The health system to the test of facts: what truth for what horizon?}

2-1- Explanations of the difficulties of the application of the system.

\section{- Problems of choice and economic and social visions}

The history and the economic practices in developing countries like Madagascar are very vague. From a communitarian choice to a liberal choice without a base on which the system must cling, the state has trouble mastering its own functioning. Since the 1980s, like Madagascar, developing countries have experienced economic performance problems with resource weaknesses. However, it is at this time that the state has adopted free healthcare in the name of the principle "health for all". A policy that necessarily exhorts an interventionist principle of the Keynesian type of State while that of the balance of resources-employment was not defined. The state quickly became asphyxiated. And the result has led the state to move to a liberal market logic with the recovery of costs and the financial participation of users in the Bamako Initiative. This without setting the anchor of its mechanism for a guarantee of durability and viability.

\section{- Absence of financial line of the system.}

As democratic as a government, any principle of gratuitousness must have financial compensation in return. The vital nature of health for the population does not mean the automatic financial availability to pay the costs of care, health having no price, but a cost. Engaged in a so-called urgency to respond to the needs, the governments have opened all the accesses of care without having the necessary means to respond in a democratic way to the needs. As the pragmatists said when you have something free, you have to think that somewhere there was someone who paid for it. The principle of the commercial economy does not accept gratuitousness.

All this, without taking into account the fact that the health system is a device at the center of offers and requests for care whose main institution is provided by the hospital. The hospital, which sometimes functions as an organization, sometimes functions as a business, needs to balance its flow of resources in order to sustain the provision of its services (Bejean, 1994).

The case since 2000 and confirmed by a recent study from 2010 shows that in Madagascar, the basic health centers are experiencing, year by year the decrease in their revenue margin for lack of low sustainability of the system of flow (Émile, 2015)

\section{- Ignorance of risk management: a burden for access to care and equity}

We know that diseases are permanent risks at the population level. The first principle seen by economists is to transform these risks into a probabilizable basis and then pool them to smooth them over time. What was at the origin of health insurance and pooling. Principles that have strengthened the health systems of developed countries. All of this was ignored completely by the Alma Ata Declaration and the Bamako Initiative. A bias that compromised both systems from the start. The former made the care free without having prepared for the 
balance of resources that it will need. The second, instead of pooling the risks, made people pay individually. However, the pooling of risks is mutually beneficial for the State and for the households: the first will have a stable package for the financing of health, the second will be covered financially in case of diseases. Individual financial participation is a double handicap: reducing access to care and making it difficult to achieve equity. France, a country that has had a fairly robust economic situation with its place as the world's 5th largest power can serve as a good lesson by having resorted to compulsory health insurance, the backbone of its health system.

\section{2-2- What approaches for an effective and sustainable health system? \\ - Mutualisation of unavoidable risks.}

The first observation that has been made is that, engaged in a collective mobilization between the countries of the same problem, and in the context of an international mobilization, the countries concerned have politically decided a kind of democratization with free healthcare ( Alma Ata) .Or, to be able to function normally, it must be remembered that a system has four functions: funding (financial function), service delivery (medical function), resource production (technical function), and 'general Administration. It is clear then that, at least in the eyes of the economists Alma Ata sinned from the first step by omitting the finance function which will feed the costs generated by "free". Health has no price, but it has a cost. Similarly for the Bamako Initiative: the financial participation of users requires individual participation. However, history and theory have confirmed that the best disease risk management is to adopt mutualisation and health insurance systems, principles completely ignored. The liberal principle supposed to regulate the imbalance did not work because facing the risks individually, the population can not ensure the good balance of the accounts. And the state, without having the blanket, can not seem to have enough resources to fill the void.

It is therefore essential for developing countries to review and propose a system that brings together the parameters that make a long-lasting and strong system. Currently, science, at least economics has found better than these two things for the management of health system accounts. Ignoring him goes right back to the wall with no hope of getting out.

The example of Gabon that has achieved a health insurance system is a good illustration to follow in this way. Since 2008, Gabon has had a compulsory health insurance scheme. Since then, $60 \%$ of the population is covered with 80 to $90 \%$ of health expenses covered .Certes, this good example is not without problems of technical order, psycho social, and others but at least the population is covered with a good economic and social mechanism, commonly accepted and successful. And the system is working gradually and improving

It is time for developing countries to mobilize massively to implement programs of redeployment of a health insurance system worthy of robust and sustainable health systems.

\section{- Political will and economic realism}

Madagascar has been independent for more than 50 years but this period, like many other developing countries, has not allowed the country to know about development. Economic problems are no longer to be demonstrated and as health and the economy influence each other, the State will have to hold a political will that goes in the positive direction of this reciprocal relationship. Keeping the health care system in its present form means maintaining a vicious circle. But to commit new principles without a perennial flow mechanism will solve no problem. It is wise to dress with a political will that meets the real needs of the people and an economic realism for the vitality of a system. 


\section{Conclusion}

The case of Madagascar is indicative of the different problems faced by many of the developing countries.

From the problems of access to care to the inefficiency of the system and the absence of equity, the health system goes around in circles. The riddles that come from the approaches and decisions taken do not correspond to the realities of the economic and social mechanisms. social. It should be remembered that the health system works like any institution with resource and employment flows. The viability of such a system must pass necessarily through the balance of these resources. But the principles of this equilibrium have not been observed one way or the other. This has weakened the functioning of the system with the main objective of improving health. It is time for these countries to pull themselves together and use all the tools, economic principles and statistics that are health insurance and pooling as part of their health system to meet the essential need of the population, health, that is a fundamental right.

\section{BIBLIOGRAPHY}

1. Bejean Sophie : Économie du système de santé : du marché à l'organisation, Économisa, 1994.

2. Brunet-Jailly Joseph: Santé : une occasion manquée? Le Mali et "l'initiative de Bamako", Afrique Contemporaine, №162. Juillet 1992.

3. Carsten Jorgensen: Denmark, changes and continuity of the health system, International Chronicle of the IRES - $\mathrm{n}^{\circ} 91$ - november 2004

4. Castonguay Joanne et al : Comparative analysis on health financing,port de projet, CIRANO, Montréal, 2007.

5. Duhamel Gilles: The American health and health insurance system: Actions with doctors concerning the quality of care and the regulation of outpatient expenditure,IGAS Rapport $\mathrm{N}^{\circ}$ 2002/0073.

6. Emile Emile : La viabilité financière des centres de santé de base : vers une nécessité de système de mutuelle et d'assurance maladie, Revue Médicale de Madagascar, 2015 $5(2) ; 544-548$.

7. Laplace et al. French and English health systems: comparative evolution since the mid-1990s ", Public Health 2002/1 (Vol. 14), p. 47-56.DOI 10.3917/spub.021.0047

8. Ridde Valery : Health Nutrition and Population, World Bank, 2004.

9. Ridde Valery :Kingdon à Bamako: conceptualiser l'implantation d'une politique publique de santé en Afrique » Politique et Sociétés, vol. 23, n² 2-3, 2004, p. 183-202.

10. Richard Blanche Nirina: Expérimentation des recouvrements de coûts en milieu hospitalier malgache, L'Harmattan, 2005.

11. Richard Blanche Nirina : Hôpital et système de soins de santé à Madagascar, L'Harmattan, 2005

12. Tizio Stéphane, Flori Yves-Antoine. The Bamako initiative: health for all or illness for everyone? In: Third World, tome 38, n¹52, 1997. pp. 837-858;

13. Tanti-Hardouin Nicolas : Views of Economists on Health Challenges in Developing Countries, 70- 2007 http://amades.revues.org/429.

14. WHO : Health financing in French.. Department "Health System Financing" (HSF) Cluster "Evidence and Information for Policy" (EIP).

15. WHO : World Health Report - For a Better Health System, Geneva, 2000 